\title{
Globalisation, National Identity and the Transformation and Renovation of Museums in France and Mainland China Yi Jiang
}

Xi'an Jiaotong-Liverpool University, Department of Architecture, Suzhou, Jiangsu, China

\section{Abstract}

In the neoliberal era, to attract more visitors, museums serve not only as cultural landmarks but also as commodities. The new role leads to a transnational and consumer-oriented subsequent form of museums. Many private museums and royal palaces are renovated into publicly accessible consumer-driven architecture. Such a transformation sometimes employs globalised identities, involving collaborative architectural practice in balanced cultural exchanges of ideas. However, since the museums are national projects, they are guided by governments more or less different agendas. So as to understand the role these governments play with, comparisons

Corresponding Author:

Yi Jiang

Yi.Jiang15@student.xjtlu.edu.cn

Received: 15 March 2019

Accepted: 25 May 2019

Published: 20 November 2019

Publishing services provided by Knowledge E

(c) Yi Jiang. This article is distributed under the terms of the Creative Commons

Attribution License, which permits unrestricted use and redistribution provided that the original author and source are credited.

Selection and Peer-review under the responsibility of the Architecture across Boundaries Conference Committee.

\section{G OPEN ACCESS}

between two national landmark museums - the Louvre Pyramid in Paris and the Northern part of the Palace Museum in Beijing - will be made here, according to their extension and renovation. The paper analyses similarities in museum situations and it investigates different renovation strategies to fulfilling the respective transformation. Moreover, it discusses causes and effects between the functions, political situations and global practices, associated with 'governmentality', referring to the economics and politics in the 1980s' France and the $21^{\text {st }}$ century's China.

Keywords: Museums, Governmentality, Renovation, the Louvre Pyramid, the Northern part of the Beijing Palace Museum, Neoliberalism

\section{Introduction: Transformation and renovation}

In The Politics of Display, Sharon Macdonald [1] perceives that capitalist production which results from globalisation has contributed to a new form of museum identity and subjectivity. The production involves more and more nation-states and tends to be led by consumers. The emergence of transformed and renovated museums serves as commodities feeding neoliberal market economies. There are many royal museums and palaces being renovated into publicly accessible architecture [2]. This is due to the majority of royal museums or palaces in any country in the world being regarded as historic landmarks that deliver cultural identity. The preservation of grand buildings requires excessive financial support from patrons. Nevertheless, some of the palaces 
are unable to accommodate a larger number of visitors and to better display of the antiques due to their spatial organisation and infrastructure. Thus, further transformation and renovations are possible.

In the late $20^{\text {th }}$ century new museums sometimes had globalised identities, rather than simply preserving their original style. Such a transformation accords with what Graham Owen [3] contends that there are two different types of architectural practice. Pre- $20^{\text {th }}$-century architecture tried to import architectural ideas from one country (usually a more dominant empire) to a less powerful country. Since the late $20^{\text {th }}$ century, the architectural practice has been collaborative and balanced in cultural exchanges of ideas, to enhance the communication between different national identities. In this case, the Grand Louvre and the Beijing Palace Museum which were both built before the $20^{\text {th }}$ century as royal palaces and renovated and extended in the modern era are worth discussing in terms of representation of various cultural identities on their extensions. The purpose of the paper is to analyse the differences in the cross-culture renovation approaches towards the Louvre and the Beijing Palace Museum under government strategies and discuss the effects on the respective building, the city and the topic of the brand under neoliberalism.

\section{What to do with Historic Royal Museums and Palaces}

When historically significant public buildings are put into service without renovation, it is sometimes difficult for old museums or palaces to hold and attract visitors using their current display of antiques. The space inside the Louvre and the Palace Museum was no longer sufficient. For instance, the Grand Louvre had a vast exhibition area, occupying $90 \%$ of the total area, but it lacked the infrastructure for mechanical equipment, cafes and shops [4]. According to Wiseman [1], after the accomplishment of Pompidou's Cultural Centre in 1977 designed by Renzo Piano and Richard George Rogers, only $30 \%$ of French nationals, of which $10 \%$ are Parisians, still visited the Grand Louvre. It means that the Louvre was losing its position in the market. Regarding the Palace Museum in Beijing, great as the number of tourists for 16.7 million visitors annually, the crowds are too many for the palaces so that the museum has to ask for early reservation with restraints on entry time. Hence, the market for the Beijing Palace Museum has been self-restricted.

To better visiting experience in a museum or a palace, it requires particular creative strategies to attract tourists and ensure tourist market demand is sustained or even grows. There were some issues to tackle in the Louvre, for instance, paintings and 
sculptures were not optimally presented, and the circulation was confusing for visitors [1]. Additionally, complicated pathways discouraged visitors from visiting the Grand Louvre. Furthermore, as Chen [5] mentions, the dean of the Palace Museum Shan said it might pose a threat to the palaces if the exhibition displays all its collection. Consequently, the Beijing Palace Museum cannot show the majority of its collections, whose number is up to 1.86 million [6]. To resolve these problems, the Grand Louvre explores its underground space and redesigns the circulation in the old and new museum; and the Chinese authorities decides to build an annexe for exhibition and restoration to the Palace Museum in Beijing.

\section{The Louvre Pyramid and the Northern part of the Beijing Palace Museum}

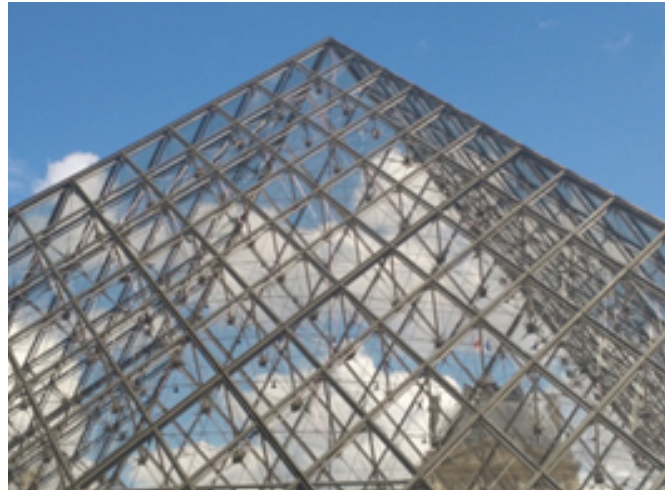

Figure 1: The Louvre Pyramid (Photograph on site,2015).

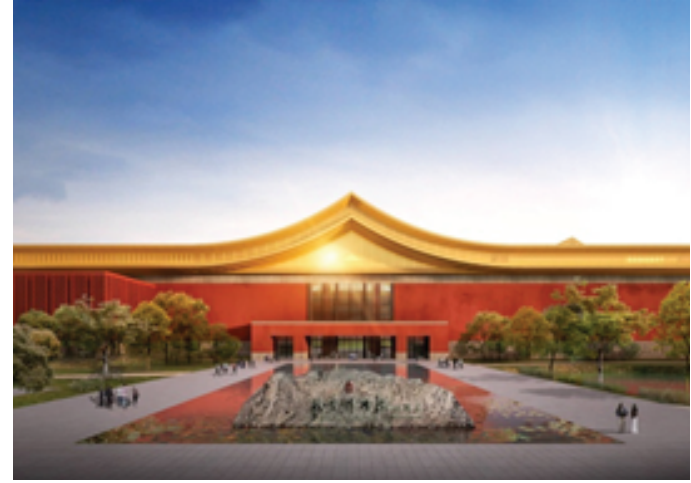

Figure 2: The northern part of the Palace Museum is in Xiyuhe Village, Haidian District, (rendering view) [5].

Commissioned by President Francois Mitterand's government, the Louvre Pyramid an extension to the Louvre Museum in Paris - was designed by Chinese born, American trained architect, I. M. Pei in 1984. I. M. Pei spent his childhood and adolescence in China and studied Architecture in America, which allows him to be mature in thinking in a 
Chinese way and be critically creative in a western thinking way [7]. The Louvre Pyramid functions as the main entrance to the Louvre Museum. The construction was finished in 1989. The glass-metal pyramid utilises not only a Western modern international style but also takes into consideration the local context (Figure 1). For this reason, it is an archetype for the renovation and construction of other museums worldwide, aiming at attracting an increasing number of tourists.

The design of the glass Louvre Pyramid has been highly influenced in other countries. Since both Paris and Beijing are the cultural and political centres of countries with a long history, the Head of the Palace Museum in Beijing, Shan, said that the renovation project which was announced and started in October 2018 takes the Louvre as a case study. The northern part of the Palace Museum is in Xiyuhe Village, Haidian District, designed by BIAD (Beijing Institute of Architectural Design). The new museum includes the antiques' exhibition and restoration (Figure 2). In terms of BIAD, this design institute is now dedicated to developing its brand as 'BIAD Design' which derives from Chinese domestic culture [8].

The transformation of the existing buildings critically changes the original image and physicality of the original buildings or the city in which they are located or both. It is of necessity because it improves the situation of the Louvre at that time and will tackle several current issues of the Beijing Palace Museum. However, despite the similarities of the purpose of their renovation for restoration and to increase tourist visitors, the regeneration design approaches of the Paris versus Beijing museums are different.

\section{Different Approaches to Renovating and Adapting His- torical Public Museums}

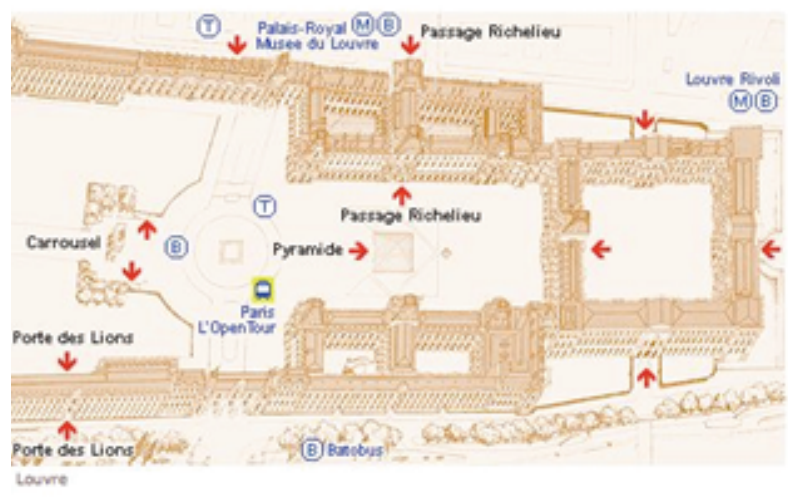

Figure 3: Plan of the Louvre [9]. 


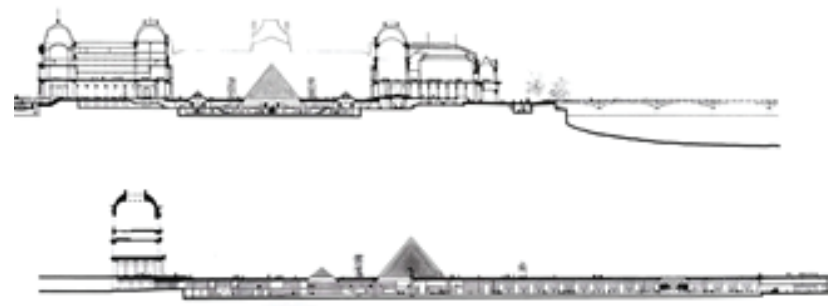

Figure 4: Section of the Louvre [1].

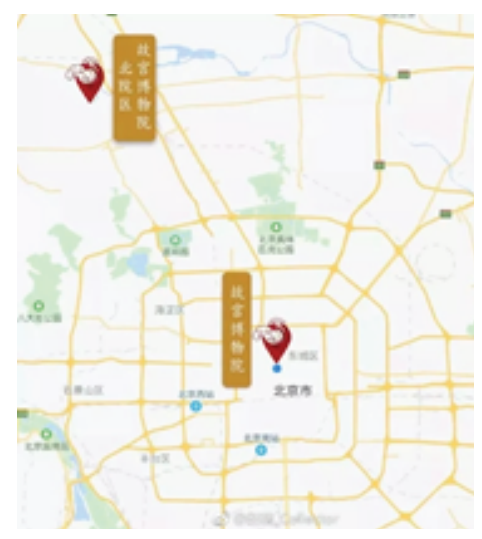

Figure 5: Map of the Beijing [5].

Although the Grand Louvre and the Beijing Palace Museum possess similar spatial restraints, they conduct design resolutions in different ways. Concerning the site, the Louvre Pyramid is located at the centre of the Cour Napoléon, surrounded by three wings of the Louvre (Figure 3). Pei takes the glass pyramid as a big roof, and space is explored by excavating the underground area to connect the original Louvre and the nearby bus station [1] (Figure 4). Whereas, the northern part of the Beijing Palace Museum is 25 kilometres away from the Forbidden City, being more independent than the Louvre Pyramid (Figure 5). The different selections of the site might result from the requirement of the functions. For instance, the Grand Louvre has entrance problems to gather visitors while the issue for the Beijing Palace Museum to tackle is to separate crowds. Furthermore, regarding materials, the glazing Louvre Pyramid has a great contrast with the traditional Baroque architecture (Figure 6). The pure shape of the Pyramid is representative of modern architecture with a globalised formal, iconic identity, while Pei also associates the shape with the pyramids in Egypt [10] whose reason might result from Napoleon's campaign in Egypt being of significance in French cultural history. Consequently, the architecture comes out with a transnational perspective. The northern part of the Palace Museum in Beijing is trying to present a national identity through its use of colours and distinctive roofs using modern construction. It follows the traditional Chinese plan of the halls, houses and courtyards, using red walls as they are 
in the Forbidden City [4]. The images follow traditional Chinese architecture while the technique of the construction is modern (Figure 7).

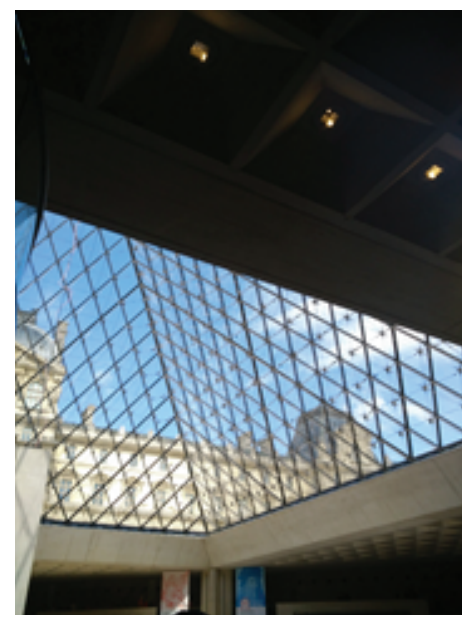

Figure 6: View from the inside to the outside (Photographed on site, 2015).
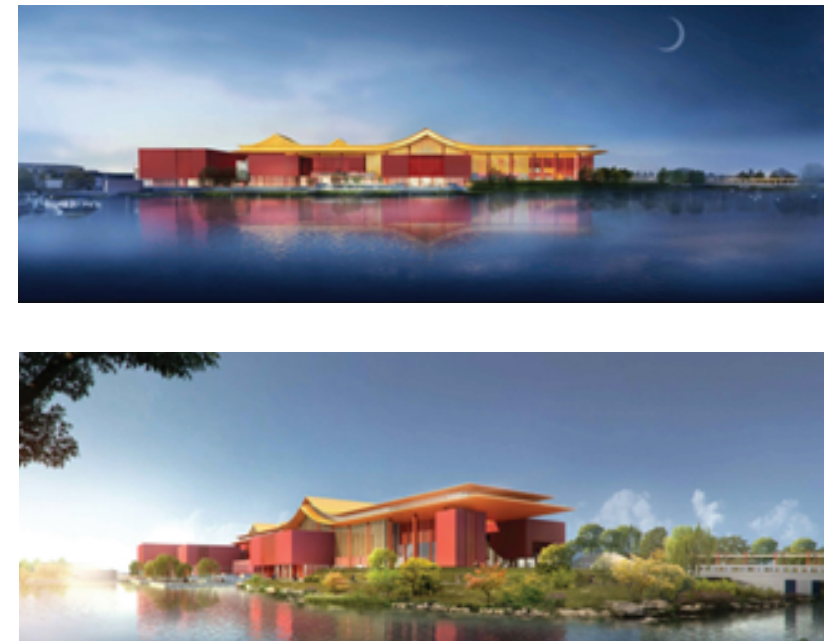

Figure 7: Rendering View of the northern part of the Palace Museum in Beijing [4]

\section{The Ambition of Governments}

The two national museums are guided by the authorities who are operating in the capitalist neoliberal era. Neoliberalism is associated with political economics [11]. According to Dean [12], governmentality is essential in taking part in national projects because it relates to 'forms of visibility' and 'forms of knowledge'. It is the art of governmentality through which state administration attempts to establish identities which showcase what a country or a city desires, aspires and believes in to the domestic and the global society by indirect approaches. Such a complex transnational identity presentation can shape the actions of citizens and influence the interaction between countries [12, 13]. 
Building architecture across cultures is the action to promote itself. The representation is either in a national style or to highlights the original national style while the material and construction generally employ an advanced approach.

Because the politics and economics in 1980s' France and the 21st's China differ in terms of motivations, museum representations differ from aligning with ideological agendas. For instance, to accelerate the development of civilisation and form an 'abstract and open' society [12] based on its own cultural identity, France employs globalised features to its national architecture, showing its positive engagement with globalisation. Situated in a Baroque complex, a triangular object which utilises the most advanced glazing technology at that time is able to achieve such a co-existence. Simultaneously, the globalised features - the implementation of transparent material sometimes assist in representing democracy nationally [14]. The interior space of such a grand national building is visible to every visitor no matter the time and no matter whether it is closed. In return, palace museums can attract visitors universally, alleviating financial stress to some extent.

France in the 1980s had the motivation to broaden its market globally and strengthen citizens' impression of democracy. Instead, China in the 21st century asks for cohesion and unity as the value of society. Since Open Door policy was carried out in 1978, similar to France in the 1980s, China desires to enhance collaboration with other countries [15]. However, China also wants to leave a powerful impression worldwide. Hence in the design of an annexe of the Beijing Palace Museum, the Chinese government focuses on transnational architectural production which uses a western structure with the symbolic interpretation of the past to showcase the cosmopolitan past of Beijing the city as well as the entire country. Moreover, the marketing strategy of the Palace Museum makes citizens more acquainted with these national organisations. On-site and online shops and the goods are designed based on the cultural identity of the museum, associated closely with citizens' daily need. Furthermore, the outcome of the goods is utilised for educational activities to promote Chinese culture which in return reinforces the cohesion of the society [16]. For example, students have the privilege for tickets and can enjoy several specifically-design routes as well as written books. Moreover, there are professional scientists giving guidance to students on discussion 'protecting and inheriting cultural heritages in the Palace Museum' [17]. Some argue the cultural products of the Louvre seem to instead target at an elite group of people, introducing so-called high culture art [18].

Because of the different motivations for the museums driven by the state clients, different types of architects are commissioned and the architecture differs in its style. 
French president at that time, Mitterrand, regarded I. M. Pei as a sophisticated architect good at combining his respect to history with innovation [1]. Furthermore, situated on the rigid axis of Paris, the design on the Louvre should consider the city as a background [19], Pei's experience in city development with property developers also made him competitive; while BIAD, the national design institute in Beijing which was founded at the beginning of the People's Republic of China is very good at Chinese national architecture with Chinese national identity. Both countries take economic and political strategies through modern governmentality. Consequently, the buildings, the city and the domain of tourism have been influenced by the art of governmentality.

\section{Influence on the Louvre and the Beijing Palace Museum, the City Paris and Beijing and the Domain of Tourism of Historic Public Museums}

Renovation and transformation make a difference to the existing old building as well as the whole city. The influence of the Louvre Pyramid is obvious while since the northern part of the Palace Museum is still under construction; it would also function as an important public building, related to the Forbidden City.

The finished Grand Louvre and the to-be-built northern part of the Palace Museum can solve the problems of space and accessibility. The two floors underground in the Louvre Pyramid allow reception to be in service. Three corridors leading to the wings of the Louvre make tourists more accessible and convenient to the works of art they want to see. Apart from the approach to the Louvre, the architecture also reinforces the intersection with the city through the west corridor towards a bus station, along which are shops and restaurants [1]. While there are two other tunnels explicitly designed for transporting the artworks, and as a result, the circulation of tourists and the antiques are clearer, enhancing efficiency. From the official coverage of the Beijing Palace Museum [20], the exhibition hall would take up $35000 \mathrm{~m}^{2}$, accounting for $34 \%$ of the total architectural area. Other essential functional spaces are provided including $20000 \mathrm{~m}^{2}$ repairing area, $23000 \mathrm{~m}^{2}$ storage and a broadcasting space accounting for $10 \%$ of space. The two museums would both enhance the interactions and the number of visitors.

The two museums highlight the tourist route in the city. The Louvre complex enhances the impression of organised symmetry at the east-west axis in the larger Parisian scheme [1]. By revitalising the east end, the avenue from the Voie Triomphe to the Grand Louvre becomes a distinct and important route of travel. Similar in Beijing, the location of the 
northern part of the Palace Museum assists in forming a route for tourists from the Summer Palace to the Badaling Great Wall and the Ming Tombs, utilising the vacant area in the north-west of Beijing.

Different representations of architecture determine whether the two buildings would become a landmark or icon. The establishment of the Louvre Pyramid could serve as a brand of the city, and the icons in the Louvre's official website uses the graphic of the Glass Pyramid (Figure 8). The branding is so successful that the authority of Abu Dhabi invited the 'Louvre' to be one of their museums [21, 22]. Like the Guggenheim (Figure 9), the Louvre, both employ modern types of museum architecture and preserve the historical style. It is likely that the state of Abu Dhabi appreciates the plurality of cultures and nationalities in the representation of museums. Whereas regarding the northern part of the Palace Museum, it is less likely to serve as an independent landmark. Instead, it is more attuned to be an affiliated place to the Palace Museum. This may be because the globalised style is easier for foreigners to accept in different regions, while a national identity may restrict its acceptability in spite of its modern technology.

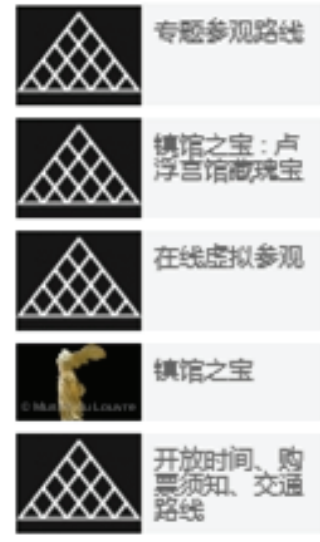

Figure 8: Icons on the official website [23]
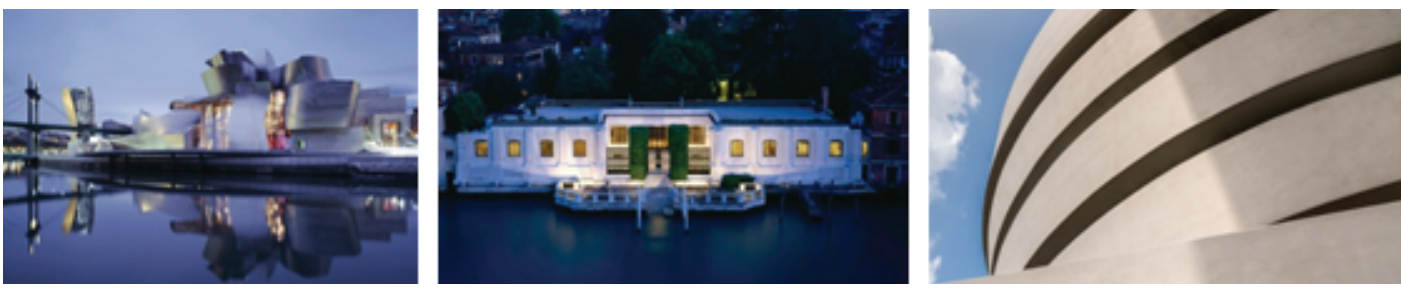

Figure 9: The Guggenheim museums [2].

\section{Conclusion: Transnational Museum}




\subsection{Transformation and renovation and governmentality}

To summarise, in the neoliberal era, it seems to be inevitable to fulfil the transformation from the grand historical palaces to great public buildings. The two national museums enact the aspiration of their governments. Governments utilise different strategies to form identities, such as defining whether it is a global feature or a local one. Hence, different styles of architecture would be selected respectively, led by different types of architects. Not only do the new Grand Louvre and the northern part of the Beijing Palace Museum compensate for the spatial weakness of the old buildings but they also contribute to an increase in tourism in the cities. However, the Grand Louvre is more successful in establishing its brand than what the Northern Part of the Beijing Palace Museum would be. The Louvre Pyramid has a unique but globalised form, paving the way for selling the brand abroad. However, concerning the northern part of the Beijing Palace Museum, it is more likely to be affiliated to the Beijing Palace Museum. Moreover, since the Palace Museum Beijing maintains a national identity, it might be more foreign to read for visitors from other countries compared with the Louvre Pyramid. Further research could be done more on the motivation and ambition of authorities and the architects.

\section{Acknowledgement}

The author would like to thank Igea Troiani (PhD) and other tutors for their contribution and support to the research. She is also thankful to all the reviewers who gave her valuable inputs to the manuscript and helped in completing the paper.

\section{Conflict of Interest}

The authors have no conflict of interest to declare.

\section{References}

[1] Macdonald, S. (1997). The Politics of Display. London: Routledge.

[2] Wiseman, C. (2001). The Architecture of I.M.Pei with an illustrated Catalogue of the Buildings and Projects. Revised edition. London: Thames \& Hudson Ltd.

[3] Owen, G. (2009). Architecture, Ethics and globalization. London: Routledge. 
[4] Guo, L.Q. (2018). Dongxizhijian: Beiyuming Jianzhu Sixiang Yanjiu [Between east and west, studies on I.M.Pei's thought on architcture]. Beijing: China Architecture \& Building Press.

[5] Chen, X. N. (2018). Building a city museum in the garden. Beijing Daily, 13 October, p.6. [Online]. Available from: http://bjrb.bjd.com.cn/html/2018-10/13/content_287588. htm (Accessed: 4 December 2018)

[6] Anonymous. The Official opening of the northern project of the Palace Museum (2018), CCTV, 11 October 2018, Video [Online]. Available from: http://tv.cctv.com/2018/ 10/11/VIDEBPoV6KPsOEuVsI91FYuX181011.shtml (Accessed: 4 December 2018)

[7] Li, N. (2010) Jiexi Beiyuming Zuopin zhongde Zhongguo Chuantong Yuansu' [Parse on Chinese Elements Beiyuming's Productions] CONSTRUCTION \& DESIGN FOR PROJECT, (5), pp. 27-29 [Online]. Available from: http://dx.doi.org/10.3969/j.issn. 1007-9467.2010.05.008 (Accessed: 13 April 2019)

[8] Jin, L. (2007) 'BIAD Sheji' Lianxiang [Thoughts on 'BIAD Design'] Architectural Creation, 4, p.15 [Online]. Available from: http://dx.doi.org/10.3969/j.issm.1004-8537. 2007.04.001 (Accessed: 13 April 2019)

[9] Anonymous (2018) The official opening of the northern project of the Palace Museum, CCTV, 11 October 2018, Video [Online]. Available from: http://tv.cctv.com/2018/10/ 11VIDEBPoV6KPsOEuVsI91FYuX181011.shtml (Accessed: 4 December 2018)

[10] Liu, L. \& Yang, A. (2013) Essay on the Collision of Chinese and French Architecture Culture at the New Millennium-an Interpretation of the Louvre Pyramid and Beijing National Grand Theatre, Journal of Beijing Institute of Civil Engineering and Architecture, 29(4), pp.1-6 [Online]. Available from: http://ez.xjtlu.edu.cn/login?url=http://search.ebscohost.com/login.aspx?direct= true $\& d b=e d s c o j \& A N=e d s c o j . b j j z g c x y x b 201304001 \&$ site=eds-live\&scope=site (Accessed: 13 April 2019)

[11] Harvey, D. (2005). A Brief History of Neoliberalism. New York: OXFORD UNIVERSITY PRESS.

[12] Dean, M. (2010). Governmentality: Power and Rule in Modern Society. London: SAGE Publications Ltd.

[13] Inda, J. X. (2005). Anthropologies of Modernity: Foucault, Governmentality, and Life Politics. USA: BLACKWELL Publishing.

[14] Ascher-Barnstone, D. (1997) Democracy and glass construction. XCSA EUROPEAN Conference, Berlin. [Online]. Available from: http://apps.acsa-arch. org/resources/proceedings/uploads/streamfile.aspx?path=ACSA.Intl.1997\&name= ACSA.Intl.1997.42.pdf (Accessed: 12 March 2019) 
[15] Ren, X. F. (2011). Building Globalization: Transnational Architecture Production in Urban China. Chicago and London: The university of Chicago press.

[16] Song, Y. S. (2018) Gugong wenchuang yinian xiaoshoue chaoshiyi, yingxiaoshouru quxianghechu [The sale of the cultural products in the Palace Museum is more than 1 billion, where is the outcome for?] Police Research \& Exploration, 7, pp.74-75 [Online]. Available from: http://ez.xjtlu.edu.cn/login?url=http://search.ebscohost.com/login. aspx?direct=true \&db=edscqv\&AN=edscqv.7000552663\&site=eds-live\&scope=site (Accessed: 14 March 2019).

[17] Shan, J. (2015) The cultural inheriting and adolescent education. Beijing Education and Science Institute [Online]. Available from: http://ez.xjtlu.edu.cn/login?url= http://search.ebscohost.com/login.aspx?direct=true\&db=edsswf\&AN=edsswf. 9316265\&site=eds-live\&scope=site (Accessed: 14 April 2019)

[18] Flinn, M.C. (2013) High Comics Art: The Louvre and the Bande Dessinee, European Comic Art, Vol. 6(2), pp.69-94 [Online]. Available from: http://dx.doi.org/0.3167/eca. 2013.060204 (Accessed: 13 March 2019)

[19] Boehm, G. (2004). Beiyuming tan Beiyuming [Conversation with I.M.Pei by Gero von Boehm]. Shanghai: Wenhui Press.

[20] The Palace Museum (2018) The Official opening of the northern project of the Palace Museum [Online]. Available from: http://www.dpm.org.cn/classify_detail/247883. html (Accessed: 4 December 2018)

[21] Furuto, A. (2012) The Louvre Abu Dhabi Museum / Ateliers Jean Nouvel' [Online]. Available from: https://www.archdaily.com/298058/the-louvre-abu-dhabi-museumateliers-jean-nouvel/ (Accessed: 4 December 2018)

[22] Gombault, A. \& Selles, D. (2018) Louvre Abu Dhabi: A Radical Innovation, But What Future for French Cultural Influence? International Journal of Arts Management, Vol. 3 (20), pp.83-94 [Online]. Available from: http://ez.xjtlu.edu.cn/login?url= http://search.ebscohost.com/login.aspx?direct=true\&db=vth\&AN=131825948\&site= eds-live\&scope=site

[23] Louvre (2018), Graph [Online]. Available from: https://www.louvre.fr/en/homepage (Accessed: 4 December 2018)

[24] Guggenheim museums (2018), Graph [Online]. Available from: https://www. guggenheim.org (Accessed: 4 March 2019) 